\title{
BMJ Open Effectiveness of the Communities Care programme on change in social norms associated with gender-based violence (GBV) with residents in intervention compared with control districts in Mogadishu, Somalia
}

Nancy Glass, ${ }^{1}$ Nancy Perrin, ${ }^{1}$ Mendy Marsh, ${ }^{2}$ Amber Clough, ${ }^{1}$ Amelie Desgroppes, ${ }^{3}$ Francesco Kaburu, ${ }^{3}$ Brendan Ross, ${ }^{4}$ Sophie Read-Hamilton ${ }^{5}$

To cite: Glass N, Perrin N, Marsh M, et al. Effectiveness of the Communities Care programme on change in social norms associated with gender-based violence (GBV) with residents in intervention compared with control districts in Mogadishu, Somalia. BMJ Open 2019;9:e023819. doi:10.1136/ bmjopen-2018-023819

- Prepublication history for this paper is available online. To view these files, please visit the journal online (http://dx.doi org/10.1136/bmjopen-2018023819).

Received 1 May 2018 Revised 24 January 2019 Accepted 5 February 2019

Check for updates

(C) Author(s) (or their employer(s)) 2019. Re-use permitted under CC BY-NC. No commercial re-use. See rights and permissions. Published by BMJ.

For numbered affiliations see end of article.

Correspondence to

Dr Nancy Glass;

nglass1@jhu.edu

\section{ABSTRACT}

Objective Determine the effectiveness of the Communities Care programme (CCP) on change in harmful social norms associated with gender-based violence (GBV) and confidence in provision of services with residents in intervention compared with control district. We hypothesised that residents in the intervention district would report a decrease in support for harmful social norms and increase in confidence in services in comparison with control district.

Setting The study was conducted in Mogadishu, Somalia. Participants In the intervention district, 192 community members (50\% women) completed baseline surveys with $163(84.9 \%)$ retained at endline. In the control district, 195 community members ( $50 \%$ women) completed baseline surveys with $167(85.6 \%)$ retained at endline.

Intervention CCP uses facilitated dialogues with community members to catalyse GBV prevention actions and provides training to diverse sectors to strengthen response services for GBV survivors.

Results Residents in the intervention district had significantly greater improvement in change in social norms: (1) response to sexual violence $(b=-0.214$, $\mathrm{p}=0.041) ;(2)$ protecting family honour $(\mathrm{b}=-0.558$, $\mathrm{p}<0.001$ ); and (3) husband's right to use violence $(b=-0.309, p=0.003)$ compared with control district participants. The greatest change was seen in the norm of 'protecting family honour' with a Cohen's $d$ effect size (ES) of 0.70 , followed by the norm 'husband's right to use violence' $(E S=0.38)$, and then the norm of 'response to sexual violence' ( $\mathrm{ES}=0.28)$. Residents in intervention district had a significantly greater increase in confidence in provision of GBV services across diverse sectors than the control district $(b=0.318, p<0.001)$ with an associated effect size of 0.67 . There were no significant differences between residents in intervention and control districts on change in personal beliefs on the norms.

Conclusion The evaluation showed the promise of CCP in changing harmful social norms associated with GBV and increasing confidence in provision of services in a complex humanitarian setting.
Strengths and limitations of this study

- The Communities Care programme is theory driven, combines primary prevention and response using a multisectoral approach and was developed for sustainability by focusing on capacity building of local partners and for scalability to conflict-affected settings worldwide.

- The study used a longitudinal community-based evaluation design in a challenging setting.

- The outcomes demonstrate the promise of a community-based violence prevention and response programme to change harmful social norms that sustain sexual violence and other forms of gender-based violence (GBV) and strengthen the multiple sector response to survivors in humanitarian settings.

- Due to the unstable environment, we have limited the evaluation of the implementation to the one intervention and one control district that were able to complete all activities of the programme, thus limiting our ability to examine differences by sex.

- The social norms measure was developed specifically for the project; to our knowledge, a social norms change measure for sexual violence and GBV did not exist.

\section{INTRODUCTION AND BACKGROUND}

Gender-based violence (GBV) remains one of the most prevalent and persistent issues facing women and girls globally. ${ }^{1-4}$ Conflict and other humanitarian emergencies place women and girls at increased risk of many forms of GBV. ${ }^{5-7}$ The Inter-Agency Standing Committee 2015 Guidelines for Integrating GBV Interventions in Humanitarian Action defines GBV as an umbrella term for any harmful act that is perpetrated against a person's will and that is based on socially ascribed (ie, gender) 
differences between women and men. It includes acts that inflict physical, sexual or mental harm or suffering, threats of such acts, coercion and other deprivations of liberty. Importantly, these harmful acts can occur in public and in private. ${ }^{8}$ There is limited information on the burden of GBV in humanitarian emergencies. One systematic review found that approximately one in five refugees or displaced women in complex humanitarian settings experienced sexual violence, though this is likely an underestimation of the true prevalence given the many barriers (eg, stigma and retaliation) to disclosure of GBV. $^{5}$ Furthermore, the fear of violence, including GBV, can force mass displacement. In a humanitarian context, some forms of GBV, especially sexual violence and sexual coercion, may occur by armed actors and others including aid workers and peacekeepers, as well as in the home by an intimate partner or other family members during the conflict, displacement and settlement in new communities and countries. ${ }^{5}$ It is important to note that women and girls are vulnerable to violence across their lifespan, not only during conflict and displacement. ${ }^{6-13}$

To advance evidence on GBV in humanitarian emergencies, in 2017, Johns Hopkins in partnership with key stakeholders (eg, Somalia ministries and authorities, World Bank, UNICEF and the United Nations Population Fund (UNFPA)) conducted a population-based survey on GBV across the three regions of Somalia. ${ }^{14}$ The survey focused on typology and scope of GBV perpetration and victimisation to improve understanding of GBV prevalence, attitudes, social norms and services. A total of 2376 women and 2257 men ( 15 years and older) consented and participated in the survey across the three regions. The findings from the survey demonstrated that GBV, including intimate partner, non-partner and childhood violence are common experiences for Somali women and girls across the life course. Individual, family and structural factors were all associated with an increase in women and girls' risk of GBV. These factors include poverty, displacement from home related to conflict or drought, minority clan status, husband/partner use of khat and harmful social norms such as family honour over survivor safety, polygamous marriages, physical and sexual violence of girls under the age of 15 years and lack of education opportunities for girls. ${ }^{14}$ Studies from other humanitarian settings have noted additional factors that underpin women's risk of GBV such as lack of mobility to safely access and limited control over resources necessary for survival (eg, fuel, shelter, food and water) and disrupted family structure and community support systems. ${ }^{13}$ 15-19 GBV has significant shortterm and long-term consequences for the safety, health, well-being and functioning for women and girls, families and communities. ${ }^{20-23}$ Often negative health and social consequences are never addressed because women and girls do not disclose GBV to providers or access healthcare or other services (eg, protection, legal and justice) because of a lack of capacity within service sectors and social norms that blame the woman or girl for the assault (eg, she was out alone after dark, she was not modestly dressed and she is working outside the home), norms that prioritise protecting family honour over safety of the survivor and community, and institutional acceptance of GBV as a normal and expected part of displacement and conflict. ${ }^{10122425}$

\section{GBV primary prevention integrated with response programmes in humanitarian settings}

Humanitarian settings have diverse governmental, international and local non-governmental organisations (NGOs) with varied levels of skill focused on increasing community and institutional awareness of GBV as a rights violation and responding to survivors through services across multiple sectors, including healthcare, education, protection and justice. ${ }^{13}$ Initiatives in humanitarian emergencies also focus on capacity building of service providers and developing programmes to respond to GBV. GBV primary prevention programmes seek to facilitate change by addressing the underlying causes and drivers of violence at a population level. Such programmes include initiatives to economically empower girls and women, institutionalisation of legal protections for GBV, enshrining women's rights and gender equality within national legislation and policy and other measures to promote gender equality. Increasingly, programmes are also targeting transformation of social norms that underpin and maintain acceptance of harmful social norms that sustain GBV.

Social norms are defined as behavioral rules to which individuals prefer to conform, conditional on their expectation that 1) most people in their relevant network conform, and 2) most people believe they should conform'. ${ }^{26}$ Social norms are different from individual beliefs or attitudes, and it is these norms, beliefs about what others think one should do, that often guide a person's actions. Even if specific individuals do not change their beliefs or attitudes, they may change their behaviour if they anticipate disapproval or negative sanctions if they do not conform to the norm. Families and communities have shared and unspoken rules that both proscribe and prescribe behaviours that lead to GBV or send messages that GBV against girls and women is acceptable, even normal. ${ }^{11} 27$ This includes norms pertaining to how individuals, families and communities value women and girls and support their rights and opportunities. ${ }^{1127}$ Community leaders, institutions and service providers, such as healthcare, education and law enforcement, can reinforce harmful norms by, for example, denying that sexual harassment and GBV exist in the school or larger community, by not believing or blaming women and girls for the sexual assault they experience when disclosing to authorities and by justifying a husband's use of physical violence as a means to discipline his wife, as correcting her behaviour is viewed as essential to protect the family's reputation in the larger community. ${ }^{27}$

Even with the multiple challenges of humanitarian settings, there is an opportunity to develop, implement 
and evaluate innovations in GBV primary prevention and response programmes. Specifically, they are settings where changes in economic, family and community structures related to displacement and conflict have created situations where social norms are challenged. For example, there is an absence of male family member(s) as they have joined an armed group or have been separated from the family during displacement requiring women to become the head of household as well as work in non-traditional roles outside the home. These changes can result in women having decision-making power and control over household financial resources and assets. This can then lead to a shift in power relations in the family and community that challenges social norms related to gender equality. These circumstances can provide an opportunity to initiate primary prevention efforts, such as those that include engaging community leaders and members in dialogues about social norms that limit and advance opportunities for women and girls and what actions can be taken by the individual, family and community to change harmful norms. ${ }^{1127}$ Acknowledging the potential of the humanitarian setting as an opportunity for primary prevention programming and recognising the need for capacity development of the response systems for GBV, UNICEF built on their work to end female genital mutilation using a social norms approach ${ }^{28}$ to develop the Communities Care Program: Transforming Lives and Preventing Violence (Communities Care) ${ }^{29}$ The goal of Communities Care is to create safer communities for women and girls through transforming harmful social norms that contribute to GBV into social norms that uphold women and girls' equality, safety and dignity. ${ }^{11} 29$

\section{Communities Care: theory-based GBV prevention and response programming}

The Communities Care programme has two objectives that are implemented through separate but inter-related strategies: (1) to increase the quality, access and coordination of compassionate care and support of women and girls who experience sexual violence and other forms of GBV in conflict-affected settings by strengthening community-based response services across diverse sectors (eg, health, psychosocial, protection and education); and (2) to change social norms that maintain and tolerate GBV and catalyse community-led prevention actions. ${ }^{29}$ Communities Care is a theory-driven programme using a social norms perspective and a feminist-informed public health approach to GBV prevention and response that draws on the ecological framework. ${ }^{112729}$ The ecological framework acknowledges the need to comprehensively address the multiple and interacting levels (eg, individual, family, community and social) of factors that cause and maintain GBV. Social norms operate within this framework and are conceptualised as beliefs of two types: (1) an individual's beliefs about what others typically do in a given situation (ie, descriptive norm) and (2) their beliefs about what others expect them to do in a given situation (ie, injunctive norm). Social norms theory suggests that for harmful behaviours to be replaced in a community, there must be a shift in collective social expectations or norms that underpin those behaviours within the community. The programme's pathway of change starts with actions (eg, coordination, capacity building, resourcing and mentorship) to strengthen the community-based response to survivors of GBV across relevant sectors (eg, health, psychosocial, law enforcement and education). ${ }^{11}$ The initial focus on survivor response services is important from an ethical perspective but also to signal that something is being done to address GBV. The next step in the pathway is to engage diverse and influential community members in structured facilitated dialogues that aim to lead to collective reflection and exploration on shared values and aspirations and to examine social norms that cause and maintain GBV. The facilitated dialogues empower diverse and influential community members to work together to discover and affirm shared positive values that promote dignity, respect and equality and to diagnose sexual violence and other forms of GBV as a problem in the community. The peer-facilitated dialogues support the group to identify harmful norms that sustain GBV and explore the benefits of change, and assuming these benefits are felt to be worth pursuing, to identify individual and collective actions to transform these norms into alternative norms that support gender equality, safety and well-being. ${ }^{11}$ Participating community members are encouraged to discuss and debate alternative behaviours that align with positive shared values of dignity, respect and fairness to replace harmful social norms that lead to violence and discrimination. Those that choose to commit to changing particular behaviours in the community then publicly share with others in the community the new ideas and ways of behaving and agree to take specific actions that support new behaviours. The final stages of the theory involve affirming and reinforcing change by communicating positive norms with others through interpersonal communication and social and mass media. Making change visible in the community reinforces that change is indeed happening, that people are taking action to prevent and respond to GBV and that it is something that they themselves can safely take part in. Communities Care helps to build an enabling environment by identifying and advocating for laws, policies, protocols and other mechanisms that support new practices and behaviours, address violations and further strengthen the capacity of institutions and services to provide competent and compassionate care for survivors

The study used a longitudinal community-based evaluation design with originally four districts in Mogadishu, Somalia, randomised to either the intervention $(n=2)$ or control district $(n=2)$. The aim of the study was to determine the effectiveness of the Communities Care programme on change in harmful social norms with residents in intervention districts compared with control districts. The main outcome is change in social norms related to GBV. The team hypothesised that residents in the intervention district would report a decrease in 
support for harmful social norms pertaining to GBV in comparison to control districts. The secondary outcomes include: (1) change in personal beliefs about GBV and (2) increase in confidence in services for GBV survivors across diverse sectors. The team hypothesised that residents in the intervention districts would report improved confidence in service response to GBV survivors compared with control districts.

This paper presents the findings from the evaluation of the initial implementation of Communities Care in Mogadishu, Somalia. As noted above, the Communities Care programme was developed and implemented from the understanding that within the humanitarian context, there is an opportunity for positive change in social norms to support gender equality and the adoption of behaviours and actions that can prevent GBV.

\section{METHODS}

\section{Study setting}

The southern and central region of Somalia has experienced more than two decades of conflict as well as ongoing emergencies including drought, famine and a large number of internally displaced people (IDP). The four districts in Mogadishu (ie, Bondhere, Karaan, Wadajir and Yaqshid) were selected based on a number of criteria, including service sectors' reports of perpetration of sexual violence and other forms of GBV, safe access and security for participation in the programme for both district residents and staff, and established relationships with national, regional and district governmental authorities and ministries to ensure access to the districts. Furthermore, critical to ethical implementation of GBV programmes, the districts needed to have local and/or international NGOs with capacity to provide services for participants that disclosed GBV and accepted referrals and an interest and willingness of local leadership and authorities to host the implementation and evaluation component of the Communities Care programme. The districts population estimates range from largest of 138000 residents (Wadajir) with $12.5 \%$ of the population identified as IDPs living in informal settlements to the smallest district (Bondhere) with an estimated 70000 residents and 12.6\% IDPs. Established residents (host community members) and IDPs in the districts participated in the programme. Importantly, when the programme implementation was planned and randomisation was completed with Bondhere and Yaqshid as intervention districts and Karaan and Wadajir randomised to control districts, the four districts were considered secure; however, security in Mogadishu is dynamic with periods of insecurity, including an increase in displaced persons moving into informal settlements from one district to another. Therefore, one of the intervention districts (Yaqshid) had multiple challenges related to insecurity and Al-Shabaab (Al-Shabaab, 'The Youth', in Arabic, is a Somali-based jihadist fundamentalist group with ties to Al-Qaeda). Since 2006 they have carried out a series of suicide bombings and violent attacks in Somalia and neighbouring countries, mainly targeting Somali government and African Union Mission to Somalia, in an attempt to control areas and impose a strict version of sharia (Islamic law)) activity during the programme implementation limiting the ability for staff and programme participants to safely complete Communities Care activities, such as gathering in groups for discussions or holding community events. In one control district (Wadajir), a large IDP movement into the district during implementation resulted in an increase in GBV and other programmes and services by diverse actors. Therefore, due to the changing sociopolitical landscape in these two districts and associated confounding factors (eg, large movement of residents from districts during the implementation and insecurity that limited ability to complete programme activities safely) these two districts, Wadajir and Yaqshid, are not included in the analyses for this paper.

\section{Study sample and procedures}

To achieve the research aims, a random sample of 200 female and male community members (15 years and older) residing in each of the districts (ie, Bondhere and Karaan) were recruited. Men and women recruited and enrolled in the community survey were not participating in the Communities Care programme activities, that is, sector response or facilitated dialogues, which allowed us to examine social norms change with the larger community, not only those participating in the programme. At recruitment, women and men were invited and consented to participate in three separate surveys (ie, baseline, midline and endline) over approximately 24 months. The community sample recruitment and enrollment was stratified based on sex, age and residence (living in IDP settlement or member of host community in the participating district). The control districts, if security allows, are offered the Communities Care programme at the end of the study.

\section{Patient and public involvement}

The team collaborated with Somalia governmental ministries, local authorities and community groups to obtain approval to identify key stakeholders (eg, religious leaders, traditional and administrative authorities, teachers, healthcare providers, GBV and human rights advocates, women's group leaders and business leaders) that have influence on beliefs, behaviours and actions in the targeted districts. These key stakeholders participated in focus groups and individual interviews to diagnose social norms that sustain GBV and advise on programme implementation. The formative research findings supported the development of the design, implementation and outcome measures for the study. The study findings have been disseminated through multiple formats, including in-country meetings (April 2018) with local implementing partners and other service agencies and discussions with key governmental ministries and local leaders in the targeted districts. 


\section{Communities Care programme implementation}

To address the first objective, to increase the quality, access and coordination of compassionate care and support of women and girls who experience sexual violence and other forms of GBV, the programme focuses on strengthening community-based services for GBV survivors. This involves identifying and addressing gaps in the availability of essential services for survivors, addressing the barriers that survivors face when trying to access services and improving the quality of care provided through capacity building of providers and community leaders. Improving quality of care and services also involves addressing harmful personal beliefs and social norms (eg, blaming woman/girl for assault) that influence providers' care, treatment and referrals for survivors. These harmful beliefs and social norms may serve to cause secondary traumatisation to survivors and/or act as a deterrent to survivors from disclosing violence and seeking help and support. To achieve objective 2, to change social norms that maintain and tolerate GBV and catalyse community led prevention actions, the Communities Care programme provides guided group discussions, support for public declarations and communication strategies for spreading new ideas and behaviours and assistance with community action planning for change. The group discussion curriculum is delivered through 15 weeks of structured and facilitated dialogues led by trained community members. Adults and adolescents (approximately 20 participants, 15 years and older per group) in single or mixed-sex groups are brought together to discuss shared values related to respect for human dignity, fairness and justice; reflect on and connect their experience of violence, including GBV, discrimination and injustice to the experiences of others; and to discuss how social norms can contribute to or prevent GBV. The individual (eg, sharing information with family members, friends and neighbours) and collective actions (eg, public declaration against GBV, youth-led theatre on gender equality, organised women's basketball and men's football match to promote gender equality and GBV prevention and GBV prevention messages included in Friday prayers) by Communities Care participants are critical to diffusion to the larger community, which is essential for social norms change. The declaration and actions act as the tipping point, the 'seeing is believing' or changing empirical expectations component of norm change theory, rather than as information dissemination, as dissemination is not adequate for behaviour change or norm change according to the theory adopted. Over the implementation of Communities Care programme in the intervention districts, the team recorded discussions and public declarations that reached, for example, 17071 people through house-to-house visits in the IDP camps and host community, 2282 teachers and students during school visits, 34 religious leaders, 128 youth group members, 154 midwives and nurses during healthcare visits and 10000 community members through radio messages.

\section{Study outcome measures}

The study measure was developed in partnership with UNICEF and implementing partners and was translated and back-translated by local Somalia team members with experience in GBV in humanitarian settings. The team also pilot tested the survey with men and women not in the targeted study districts, allowing for revisions prior to final implementation. The baseline survey in the intervention (Bondhere) and control (Karaan) districts was initiated after recruitment and randomisation but prior to implementation of the Communities Care programme. The survey consisted of demographic questions (eg, age, sex, education, marital status and number of children in household), the Social Norms and Beliefs about GBV Scale and measures of confidence in GBV service providers used in similar low-resource and conflict-affected settings.

\section{Social Norms and Beliefs about GBV Scale}

At the time of the project, to the project team's knowledge, there were no social norms measures that specifically addressed GBV that had been developed or previously used in humanitarian settings. The lack of social norms measures for GBV is likely associated with the multiple theoretical and disciplinary perspectives and understandings of social norms, including how norms differ from personal beliefs, opinions, attitudes and behaviour. ${ }^{11}{ }^{30}$ As noted by Heise and Manji, ${ }^{31}$ efforts to measure social norms related to GBV have resulted in collecting information on beliefs and attitudes towards GBV rather than social norms. To measure changes in social norms, a person must be asked about a norm from multiple perspectives, including personal beliefs towards a specific norm, beliefs about how influential others (eg, parents, religious leaders, peers and teachers) expect one should behave (ie, normative expectations) and beliefs about how one believes others in the community behave (ie, empirical expectations). ${ }^{11} 2831$

The Social Norms and Beliefs about GBV Scale for the study was informed by a group of experts in social norms, GBV, humanitarian emergencies and psychometrics during a global advisory board meeting that UNICEF convened in early 2013. Furthermore, the team collaboratively used formative research with multiple stakeholders in Somalia (eg, male/female IDPs and host community members 15 years and older, service providers, administrative and traditional leaders) to develop the measure. For this study, we focused on developing a measure of injunctive norms-in this case beliefs about what influential others (eg, parents, siblings, peers, religious leaders and teachers) expect individuals to do in the case of GBV. Once developed, the team conducted a psychometric evaluation of the Social Norms and Beliefs about GBV Scale to ensure a reliable and valid measure of change in social norms related to sexual violence and other forms of $\mathrm{GBV}$, which was the main outcome for the Communities Care programme evaluation. The scale was administered to 602 randomly selected community members age 15 years and older across Mogadishu, Somalia, and Yei and 


\section{Box 1 Social norms measure}

\section{Response to sexual violence (five items)}

1. How many of these people whose opinion matters most to you expect a husband to abandon his wife if she reports that she has been raped?

2. How many of these people whose opinion matters most to you expect the family to ignore/reject a daughter if she reports that she has been raped?

3. How many of these people whose opinion matters most to you accept sexual violence against women and girls a normal part of life?

4. How many of these people whose opinion matters most to you blame women/girls when they are raped?

5. How many of these people whose opinion matters most to you think that a man should have the right to demand sex from a woman or girl even if he is not married to her?

\section{Protecting family honour (six items)}

1. How many of these people whose opinion matters most to you expect women/girls to not report rape to protect the family dignity?

2. How many of these people whose opinion matters most to you expect that a woman/girl's reputation will be damaged, if she reports sexual violence to the authorities or elders?

3. How many of these people whose opinion matters most to you fear stigma if they were to report sexual violence?

4. How many of these people whose opinion matters most to you expect sexual violence to be handled within the family and not reported to authorities?

5. How many of these people whose opinion matters most to you expect a husband or father to retaliate against the alleged perpetrators?

6. How many of these people whose opinion matters most to you expect women and girls to only report sexual violence if they have serious physical injuries?

\section{Husband's right to use violence (four items)}

1. How many of these people whose opinion matters most to you think that when a man beats his wife, he is showing his love for her?

2. How many of these people whose opinion matters most to you think that a man has the right to beat/punish his wife?

3. How many of these people whose opinion matters most to you think it is okay for a husband to beat his wife to discipline her?

4. How many of these people whose opinion matters most to you expect a husband to force his wife to have sex when she does not want to?

Warrup, South Sudan. The psychometric properties of the 15-item scale are strong. Each of the three subscales, 'response to sexual violence,' 'protecting family honour' and 'husband's rights to use violence' within the two domains, personal beliefs and injunctive norms, illustrate good factor structure and acceptable internal consistency and reliability. For example, Cronbach's alpha reliabilities, a measure of internal consistency of the scale, were in an acceptable range for all factors/subscales within each domain. Cronbach's alpha ranged from 0.69 to 0.75 for the injunctive norms domain and 0.71 to 0.77 for the personal belief domain. The manuscript on the development and psychometric evaluation of the Social Norms and Beliefs about GBV Scale has been submitted for publication, but details are available on request from the lead author.
The Social Norms and Beliefs about GBV Scale (box 1) first asked participants to identify influential others in their lives and communities whose opinions matter to them. Typically, the influential other is identified as a father, mother, husband, wife, other family member, religious leader, traditional leader and/or friend. Once the influential others were identified, the research assistants (RAs) read each of the 15 items on the measure comprised of three subscales: (1) response to sexual violence (five items, Cronbach's alpha=0.82); (2) protecting family honour (six items, Cronbach's alpha=0.71); and (3) husband's right to use violence (four items, Cronbach's alpha $=0.71$ ). For example, the RA reads, 'How many of these people whose opinion matters most to you blame women/ girls when they are raped'. The responses are recorded on a Likert scale that ranges from 'none of them' to 'all of them'.

In addition to the injunctive norms domain questions, we did ask each participant about their beliefs related to sexual violence and GBV. The same 15 items of the injunctive norms were used to assess personal beliefs. The personal belief questions started with, 'we would like to know if you think any of the following statements are wrong and how ready or willing you are to take action by speaking out publicly on the issue'. For example, 'women and girls should be blamed if they are raped'. The Likert scale had four responses: (1) agree with this statement; (2) not sure if I agree or disagree with the statement; (3) disagree with the statement but not ready to tell others that I disagree; and (4) I am telling others that the statement is wrong. Cronbach's alphas for the three personal beliefs subscales are acceptable and included: (1) response to sexual violence $=0.74$; (2) protecting family honour $=0.65$; and (3) husband's right to use violence $=0.68$.

\section{Confidence in GBV services}

Participants were asked 17 items on a 4-point Likert scale (ie, strongly disagree to strongly agree) as the extent to which they have confidence in the provision of GBV services across the multisector response. Examples of the items include, 'health care providers will provide confidential care to GBV survivors' and 'police will treat GBV survivors with respect and kindness'. The confidence items were asked for the criminal justice, healthcare, formal and informal legal and education sectors.

\section{Data collection and management}

The local implementing partners had established relationships with community leaders, but prior to implementing data collection, trained female and male RAs visited community authorities in each district and asked the leaders to designate one 'community guide' for each RA. The community guides helped the RAs to safely move and find their way around the district neighbourhoods. To cover the area that each RA had been assigned, he or she started from a central point determined with the community guide and knocked on the door of every third house/dwelling. If nobody was home or the 
person they met at the house/dwelling was not willing to participate or did not match the sampling target for sex/age, the RA went to the next house/dwelling. Once a participant who met the targeted sex/age was identified and agreed to participate, the RA worked with the participant to find a private and comfortable place to provide informed consent and administer the survey. A survey was completed with only one eligible participant in each household. The RA provided each participant with informed consent information using the script approved by the in-country team, appropriate Somalia governmental ministries and the Johns Hopkins Medical Institution Institutional Review Board (IRB). If the participant provided verbal consent, the RA administered the survey and recorded responses on the study tablet. Given the longitudinal nature of the study, the retention of participants over the 2-year follow-up was critical to success. The RAs asked all participants at time of baseline interview for safe contact information for themselves and at least one trusted family member, neighbour and so on including cell phone numbers to call or send SMS as reminders of upcoming surveys. Personal data were not stored with data collected on the surveys. Participants were given a $\$ 4, \$ 6$ and $\$ 8$ food voucher respectively for their expertise and time completing each survey. At the end of each day, the RA supervisor connected all the study tablets to the wireless internet in the office and uploaded the data to the secure server hosted by Johns Hopkins and documented the number of surveys completed in the sampling frame to monitor progress. Once the data were uploaded, it was automatically removed from the tablets. No study related information was shared with anyone outside the research team.

\section{Ethics approval and consent to participate}

The government ministry provided a letter of approval to Johns Hopkins and the local implementing partners to use as they reached out to authorities and key stakeholders to implement the research in each participating district.

\section{Study analysis}

As indicated above, two of the districts (Yaqshid: intervention, and Wadajir: control district) were removed from the analysis because of the safety, security and changes in the community and services that challenged participants and staff in the districts, making it difficult to complete the programme activities and evaluation. The primary outcome is change from baseline to endline in harmful social norms that sustain sexual violence and other forms of GBV as measured by the three subscales (ie, response to sexual violence, protecting family honour and husband's right to use violence) of the Social Norms and Beliefs about GBV Scale. Secondary outcomes include participants' personal beliefs about response to sexual violence, protecting family honour and husband's right to use violence and confidence in provision of services across diverse sectors for women and girls that experience sexual violence and other forms of GBV.

Regression was used to compare the intervention and control districts on change in primary and secondary outcomes. The dependent variable was change score (ie, baseline to endline) with a binary indicator for intervention versus control district as the predictor variable. T-tests and $\chi^{2}$ analyses were conducted to determine differences between the intervention and control districts in demographic characteristics at baseline. Analyses are based on completers only. Study participants that were lost to follow-up (eg, moved out of the district) or withdrew from the study were compared with those who remained in the study using t-tests and $\chi^{2}$ analyses.

\section{RESULTS}

In the intervention district, there were 192 community members (50\% women) that completed baseline surveys with $163(84.9 \%)$ retained at endline. In the control district, 195 community members (50\% women) completed baseline surveys with $167(85.6 \%)$ retained at endline. Table 1 presents the demographic characteristics of the participants in each district. As expected, the participants did not differ on age, sex or displacement status due to stratified sampling. There was also no difference on marital status, having children in the home, education level or work status. Over half $(53.2 \%)$ of participants are married with the majority $(63.3 \%)$ having children. Slightly more than half (52\%) had never attended school. Less than one-quarter $(22.7 \%)$ of participants were currently working outside the home. Participants in the intervention and control districts did differ significantly on monthly financial status, with intervention district participants having poorer financial status than participants in the control district. The 57 participants that were lost to follow-up (endline survey) did not differ significantly from completers on age or sex.

\section{Primary outcomes}

Men and women participants in the intervention district had significantly greater improvement in change in harmful social norms for all three of the subscales: (1) response to sexual violence $(b=-0.214, p=0.041)$; (2) protecting family honour $(\mathrm{b}=-0.558, \mathrm{p}<0.001)$; and $(3)$ husband's right to use violence $(b=-0.309, p=0.003)$ than participants in the control district. The greatest change was seen in the norm of 'protecting family honour' with a Cohen's d effect size of 0.70 , followed by the norm of 'husband's right to use violence' ( $\mathrm{ES}=0.38$ ), and then the norm of 'response to sexual violence' ( $\mathrm{ES}=0.28)$. Table 2 summarises the findings for the primary and secondary outcomes. The harmful norm response to sexual violence remained the same in the intervention district over time but increased in the control district. The change in the norm of protecting family honour occurred in both the intervention and control districts with a significantly greater improvement reported in the intervention district. 


\begin{tabular}{|c|c|c|c|}
\hline & $\begin{array}{l}\text { Intervention } \\
\mathrm{n}=192(\%)\end{array}$ & $\begin{array}{l}\text { Control } \\
n=195(\%)\end{array}$ & $P$ value \\
\hline Per cent female & 50.5 & 50.8 & 0.360 \\
\hline Age (years) & & & 0.850 \\
\hline $15-17$ & 24.5 & 25.1 & \\
\hline $18-24$ & 25.0 & 25.1 & \\
\hline $25-44$ & 25.0 & 24.1 & \\
\hline $45-60$ & 24.5 & 23.1 & \\
\hline Over 60 & 1.0 & 2.6 & \\
\hline Displaced & & & 0.783 \\
\hline Currently displaced & 8.3 & 8.2 & \\
\hline Previously displaced & 41.7 & 43.1 & \\
\hline Never displaced & 49.5 & 48.7 & \\
\hline Marital status & & & 0.277 \\
\hline Married & 57.3 & 49.2 & \\
\hline Widowed & 4.2 & 4.6 & \\
\hline Divorced/separated & 8.3 & 13.8 & \\
\hline Abandoned & 0.5 & 0 & \\
\hline Never married & 29.7 & 32.3 & \\
\hline Have children & 65.1 & 61.5 & 0.490 \\
\hline Education & & & 0.114 \\
\hline None & 51.2 & 51.8 & \\
\hline Some primary & 21.9 & 22.1 & \\
\hline Completed primary & 13.0 & 16.9 & \\
\hline Some secondary & 2.1 & 4.6 & \\
\hline Completed secondary & 6.3 & 4.1 & \\
\hline Some college & 4.2 & 0.5 & \\
\hline Completed college & 0.5 & 0 & \\
\hline Currently working & 22.9 & 22.6 & 0.910 \\
\hline Monthly financial status & & & $<0.001$ \\
\hline $\begin{array}{l}\text { Can meet basic needs } \\
\text { of the family }\end{array}$ & 1.0 & 5.6 & \\
\hline $\begin{array}{l}\text { Can meet basic needs } \\
\text { of the family most but } \\
\text { all of the month }\end{array}$ & 14.1 & 15.9 & \\
\hline $\begin{array}{l}\text { Can meet basic needs } \\
\text { of the family for } 1 / 2 \\
\text { month }\end{array}$ & 7.8 & 20.5 & \\
\hline $\begin{array}{l}\text { Can meet basic needs } \\
\text { of the family for less } \\
\text { than } 1 / 2 \text { the month }\end{array}$ & 13.0 & 18.5 & \\
\hline $\begin{array}{l}\text { Never have enough } \\
\text { money to meet the } \\
\text { basic needs of the } \\
\text { family }\end{array}$ & 64.1 & 39.5 & \\
\hline
\end{tabular}

The change in the norm husband's right to use violence improved in the intervention community and declined in the control district. Although the study was not powered to examine the effect on the primary outcomes for men and women, we did calculate the effect sizes separately.
The intervention appears to have a stronger effect for women on response to sexual violence $(\mathrm{ES}=-0.42$ for women, $\mathrm{ES}=-0.11$ for men) and husband's right to use violence ( $\mathrm{ES}=-0.49$ for women, $\mathrm{ES}=-0.30$ for men) and a slightly stronger effect for men on protecting family honour ( $\mathrm{ES}=-0.68$ for women, $\mathrm{ES}=-0.75$ for men).

\section{Secondary outcomes}

There were no significant differences between the participants in intervention and control districts on change in personal beliefs on the harmful norms: (1) response to sexual violence $(b=-0.092, p=0.379) ;(2)$ protecting family honour $(b=0.196, p=0.102)$; and (3) husband's right to use violence $(b=-0.167, p=0.209)$. The participants in the intervention district had a significantly greater increase in report of confidence in service providers across diverse sectors available for women and girls that have experienced sexual violence and other forms of GBV than the control districts $(b=0.318, p<0.001)$ with an associated effect size of 0.67 . The intervention had a stronger effect on men's confidence in provision of services than women's ( $\mathrm{ES}=1.00$ for men, $\mathrm{ES}=0.45$ for women).

\section{DISCUSSION}

The evaluation of the Communities Care programme demonstrates the promise of theoretically driven and community-based initiatives that promote changes in harmful social norms that sustain sexual violence and GBV and strengthen response services in humanitarian settings. GBV prevention programming is an emerging area of practice, particularly in humanitarian contexts. Until recently, and like in many efforts to address GBV globally, efforts to prevent GBV among conflict and disaster-affected populations have centred on behaviour change approaches using methodologies premised on knowledge and awareness as key determinants of behaviour change. Communities Care is among a new generation of prevention programmes that are focused on transformation of social norms and gender relations by directly addressing the structural and societal conditions that sustain gender inequality. The findings from Communities Care contribute to the small but growing number of primary prevention programmes that use a gender transformative framework in humanitarian settings. The majority of previous efforts focused on economic empowerment incorporating components on gender equality and/or assessed the impact of economic programming on partner violence. The findings from the evaluation of the pilot implementation of Communities Care in Somalia and other existing programme evaluations in humanitarian settings suggest that carefully designed, community engaged, multipronged interventions that target social norms underpinning GBV and catalyse community-led mobilisation efforts may over time change harmful norms and foster norms that promote gender equality. Promising primary prevention interventions build knowledge and awareness about GBV and create opportunities for public and private reflection, 
Table 2 Means (SD), regression coefficient ( $p$ value) and effect sizes for primary and secondary outcomes

\begin{tabular}{|c|c|c|c|c|c|c|}
\hline & \multicolumn{2}{|c|}{ Intervention, $n=163$} & \multicolumn{2}{|c|}{ Control, $n=167$} & \multirow{2}{*}{$\begin{array}{l}\text { b } \\
\text { (P value) }\end{array}$} & \multirow[b]{2}{*}{ Effect size } \\
\hline & Baseline & Endline & Baseline & Endline & & \\
\hline \multicolumn{7}{|l|}{ Social norms* } \\
\hline Protecting family honour & $3.21(0.64)$ & $2.60(0.56)$ & $2.67(0.86)$ & $2.62(0.57)$ & $-0.558(<0.001)$ & -0.70 \\
\hline Husband's right to use violence & $2.82(0.77)$ & $2.59(0.56)$ & $2.40(0.80)$ & $2.48(0.60)$ & $-0.309(0.003)$ & -0.38 \\
\hline \multicolumn{7}{|l|}{ Personal beliefs $†$} \\
\hline Negative response to sexual violence & $3.13(0.63)$ & $2.99(0.80)$ & $3.08(0.73)$ & $3.03(0.78)$ & $-0.092(0.379)$ & -0.13 \\
\hline Protecting family honour & $2.53(0.73)$ & $2.90(0.80)$ & $2.65(0.85)$ & $2.81(0.88)$ & $0.196(0.102)$ & 0.27 \\
\hline Husband's right to use violence & $2.56(0.88)$ & $2.78(0.91)$ & $2.28(0.83)$ & $2.66(0.90)$ & $-0.167(0.209)$ & -0.18 \\
\hline $\begin{array}{l}\text { Confidence in service providers across } \\
\text { sectors } \ddagger\end{array}$ & $2.91(0.56)$ & $2.98(0.45)$ & $3.14(0.35)$ & $2.89(0.41)$ & $0.318(<0.001)$ & 0.67 \\
\hline
\end{tabular}

*Social norms questions asked how many of the people whose opinion matters most to you endorse each statement with a response scale of: 1: none of them; 2: a few of them; 3 : about half of them; 4: most of the them; 5 : all of them. Higher scores mean more negative social norms.

†Personal belief questions used the response scale of: 1: agree with this statement; 2 : are not sure if you agree or disagree with the statement; 3: disagree with the statement but are not ready to tell others that you disagree with it; 4: telling others that this is wrong. Higher scores mean more positive personal beliefs.

$\ddagger$ Confidence in service providers response scale: 1: strongly disagree; 2: disagree; 3: agree; 4: strongly agree. Higher scores mean greater confidence in service providers.

discussion and dialogue about harmful social norms that sustain inequality, discrimination and violence and mobilise community leaders and members to take action to prevent and respond to GBV.

The Communities Care programme is innovative and contributes to future intervention and evaluation work in conflict-affected settings in several key ways. The programme is theory driven and links primary prevention and response using a multisectoral approach and was developed for sustainability by focusing on capacity building of local partners and for scalability to conflict-affected settings worldwide. The conducting of the evaluation itself is innovative, as few programmes in conflict-affected settings are rigorously evaluated. Longitudinal research is needed to examine the effectiveness of interventions and programming in conflict-affected areas. These contexts pose ethical and logistical challenges to conducting such research, particularly when examining a sensitive topic such as GBV; however, this evaluation serves as an example of the ability to conduct longitudinal evaluations in challenging settings. Furthermore, an important contribution of this evaluation is the creation of a reliable and valid social norms measure, the Social Norms and Beliefs about GBV Scale, which did not exist previously and can be used in future evaluations of social norms change programmes in diverse settings.

\section{Limitations}

This study has limitations. The evaluation was conducted in four districts in Mogadishu; however, during the course of the pilot implementation, two of the districts (one intervention and one control) had significant challenges, making it difficult to impossible to complete programme activities. For example, given the security issues, participants did not feel safe in gathering as a group as part of the 15-week discussion group activities, likely limiting the reach and impact of the Communities Care programme; therefore, the evaluation of the implementation is for one intervention and one control district that were able to complete all activities of the programme. The lack of access to the study districts reduced the sample size, thus limiting our ability to examine differences by sex and age. The experiences of the female and male community members in the two districts are not generalisable to all districts throughout Mogadishu or other humanitarian settings. Additionally, the Social Norms and Beliefs about GBV Scale was developed specifically for the project. The three subscales that made up the injunctive norm domain had acceptable Cronbach's alpha $(>0.70)$, with response to sexual violence: Cronbach's alpha $=0.82$, protecting family honour: Cronbach's alpha $=0.71$ and husband's right to use violence: Cronbach's alpha $=0.71$. We saw slightly lower Cronbach's alphas for two of the three personal beliefs subscales: protecting family honour $=0.65$ and husband's right to use violence $=0.68$ but within the acceptable range. We recommend additional reliability and validity testing of the Social Norms and Beliefs about GBV Scale in diverse global and humanitarian settings.

\section{CONCLUSIONS}

Settings affected by conflict and displacement present an opportunity for GBV primary prevention and response programmes to facilitate population level change by replacing the social norms that maintain violence against women and girls. The evaluation showed that community 
members in the district receiving Communities Cares had significantly greater improvement in change in harmful social norms associated with GBV. The outcomes of the evaluation demonstrate the potential of a community-based and community-led initiative to change harmful social norms that sustain GBV and strengthen GBV response services for survivors in humanitarian settings.

\section{Author affiliations}

${ }^{1}$ School of Nursing, Johns Hopkins University, Baltimore, Maryland, USA

${ }^{2}$ UNICEF USA, New York City, New York, USA

${ }^{3}$ Comitato Internazionale per lo Sviluppo dei Popoli (CISP) Somalia, Nairobi, Kenya

${ }^{4}$ UNICEF Somalia, Mogadishu, Somalia

${ }^{5}$ Gender-based violence in Emergencies, Sydney, Australia

Acknowledgements The study team would like to acknowledge and thank the implementing partner team members and research assistants in Mogadishu who used their expertise to conduct the programme and collected the data for the evaluation. We also would like to acknowledge and thank all the participants and residents of the intervention and control districts who gave their time and expertise.

Contributors NG, NP, MM and SR-H designed the study methodology and designed the survey with input from all coauthors. NG, NP and AC trained the research team. $A D$ and FK directed field implementation and oversaw recruitment and followup with participants. NP conduced the data analysis. All authors interpreted the findings and drafted the manuscript. All coauthors provided significant input in the revision and final approval of the manuscript and met the ICMJE authorship requirements.

Funding UNICEF (RFPS-USA-2012-501534).

Competing interests None declared.

Patient consent for publication Not required.

Ethics approval Johns Hopkins Medical Institution Institutional Review Board.

Provenance and peer review Not commissioned; externally peer reviewed.

Data sharing statement The Communities Care programme toolkit is available through UNICEF. We will make the data and associated documentation available to users only under a data-sharing agreement that provides for: (1) a commitment to using the data only for research purposes and not to identify any individual participant; (2) a commitment to securing the data using appropriate computer technology; and (3) a commitment to destroying or returning the data after analyses are completed.

Open access This is an open access article distributed in accordance with the Creative Commons Attribution Non Commercial (CC BY-NC 4.0) license, which permits others to distribute, remix, adapt, build upon this work non-commercially, and license their derivative works on different terms, provided the original work is properly cited, appropriate credit is given, any changes made indicated, and the use is non-commercial. See: http://creativecommons.org/licenses/by-nc/4.0/.

\section{REFERENCES}

1. Decker MR, Latimore AD, Yasutake S, et al. Gender-based violence against adolescent and young adult women in low- and middleincome countries. J Adolesc Health 2015;56:188-96.

2. Devries KM, Mak JY, García-Moreno C, et al. Global health. The global prevalence of intimate partner violence against women. Science 2013;340:1527-8.

3. Watts C, Zimmerman C. Violence against women: global scope and magnitude. Lancet 2002;359:1232-7.

4. Garcia-Moreno C, Jansen HA, Ellsberg M, et al. Prevalence of intimate partner violence: findings from the WHO multi-country study on women's health and domestic violence. Lancet 2006;368:1260-9.

5. Vu A, Adam A, Wirtz A, et al. The prevalence of sexual violence among female refugees in complex humanitarian emergencies: a systematic review and meta-analysis. PLoS Curr 2014;6.

6. Wirtz AL, Pham K, Glass N, et al. Gender-based violence in conflict and displacement: qualitative findings from displaced women in Colombia. Confl Health 2014;8:10.
7. Sloand E, Killion C, Gary FA, et al. Barriers and Facilitators to Engaging Communities in Gender-Based Violence Prevention following a Natural Disaster. J Health Care Poor Underserved 2015;26:1377-90.

8. IASC. Guidelines for integrating gender-based violence interventions in humanitarian action: Reducing risk, promoting resilience and aiding recovery. Geneva: IASC, 2015.

9. Hynes M, Robertson K, Ward J, et al. A determination of the prevalence of gender-based violence among conflict-affected populations in East Timor. Disasters 2004;28:294-321.

10. Wirtz AL, Glass N, Pham K, et al. Development of a screening tool to identify female survivors of gender-based violence in a humanitarian setting: qualitative evidence from research among refugees in Ethiopia. Confl Health 2013;7:13.

11. Read-Hamilton S, Marsh M. The Communities Care programme: changing social norms to end violence against women and girls in conflict-affected communities. Gender \& Development 2016;24:261-76.

12. Stark $\mathrm{L}$, Warner $A$, Lehmann $\mathrm{H}$, et al. Measuring the incidence and reporting of violence against women and girls in liberia using the 'neighborhood method'. Confl Health 2013;7:20.

13. Tappis H, Freeman J, Glass N, et al. Effectiveness of Interventions, Programs and Strategies for Gender-based Violence Prevention in Refugee Populations: An Integrative Review. PLoS Curr 2016;8.

14. Wirtz A, Perrin N, Glass N, et al. Lifetime prevalence, correlates, and health consequences of gender-based violence victimization and perpetration among men and women in Somalia. Washington DC: World Bank, 2017.

15. Ager A, Boothby N, Bremer M. Using the 'protective environment' framework to analyse children's protection needs in Darfur. Disasters 2009;33:548-73.

16. Cardoso LF, Gupta J, Shuman S, et al. What Factors Contribute to Intimate Partner Violence Against Women in Urban, Conflict-Affected Settings? Qualitative Findings from Abidjan, Côte d'Ivoire. J Urban Health 2016;93:364-78.

17. Rubenstein BL, Stark L. The impact of humanitarian emergencies on the prevalence of violence against children: an evidence-based ecological framework. Psychol Health Med 2017;22:58-66.

18. Tol WA, Stavrou V, Greene MC, et al. Sexual and gender-based violence in areas of armed conflict: a systematic review of mental health and psychosocial support interventions. Confl Health 2013;7:16.

19. Jewkes R. Intimate partner violence: causes and prevention. Lancet 2002;359:1423-9.

20. Gruskin S, Safreed-Harmon K, Moore CL, et al. HIV and genderbased violence: welcome policies and programmes, but is the research keeping up? Reprod Health Matters 2014;22:174-84.

21. Vyas S, Jansen HA, Heise L, et al. Exploring the association between women's access to economic resources and intimate partner violence in Dar es Salaam and Mbeya, Tanzania. Soc Sci Med 2015;146:307-15.

22. Sidel VW, Levy BS. The health impact of war. Int J Inj Contr Saf Promot 2008;15:189-95.

23. Gupta J, Falb KL, Carliner H, et al. Associations between exposure to intimate partner violence, armed conflict, and probable PTSD among women in rural Côte d'Ivoire. PLoS One 2014;9:e96300.

24. McCleary-Sills J, Namy S, Nyoni J, et al. Stigma, shame and women's limited agency in help-seeking for intimate partner violence. Glob Public Health 2016;11:224-35.

25. Wirtz AL, Glass N, Pham K, et al. Comprehensive development and testing of the ASIST-GBV, a screening tool for responding to genderbased violence among women in humanitarian settings. Confl Health 2016;10:7.

26. Bicchieri C. The Grammar of Society: the nature and dynamics of social norms. New York: Cambridge University Press, 2006.

27. Glass N, Perrin N, Clough A, et al. Evaluating the communities care program: best practice for rigorous research to evaluate gender based violence prevention and response programs in humanitarian settings. Confl Health 2018;12.

28. Mackie G, Moneti F, Shakya H, et al. What are social norms? How are they measured? New York: UNICEF/UCSD Center on Global Justice, 2015.

29. UNICEF. Communities care: transforming lives and preventing violence toolkit. New York: UNICEF, 2014

30. Alexander-Scott M, Bell M, Holden J. DFID Guidance Note: Shifting Social Norms to Tackle Violence Against Women and Girls (VAWG). London: DFID Violence Against Women Helpdesk, 2016.

31. Heise L, Manji K. Social Norms, GSDRC Professional Development Reading Pack No. 31. Birmingham: University of Birmingham, 2016. 